\title{
ANALISIS INPUT (MAN AND METHODE) PELAKSANAAN ANC DI WILAYAH KERJA PUSKESMAS IV KOTO
}

\author{
Lydia Mardison Putri ${ }^{1}$ \\ Program pendidikan Ners, Sekolah Tinggi Ilmu Kesehatan Fort De Kock Bukittinggi \\ Lydia.mardison2@gmail.com
}

Submitted: 30-08-2018, Reviewer: 09-09-2018, Accepted: 17-10-2018

\begin{abstract}
ABSTRAK
Peningkatan angka abortus di Wilayah Kerja Puskesmas Kecamatan IV Koto Tahun 2016 yang terus meningkat, menurut Putri (2018) disebabkan oleh Ante Natal Care (ANC) tidak berkualitas tidak sesuai dengan standar pelayanan ANC terpadu Permenkes No 97 Tahun 2014 untuk itu perlu penelitian lanjut untuk mencari penyebab ANC tidak berkualitas tersebut. Penelitian ini bertujuan untuk menganalisis input man and method pelaksanaan ANC diwilayah kerja Puskesmas Kecamatan IV Koto Kabupaten Agam. Penelitian ini menggunakan desain penelitian kualitatif dengan pendekatan sistem, pengumpulan data menggunakan tehnik triangulasi sumber dan analisa data menggunakan Huberman model. Hasil penelitian menemukan bahwa tenaga kesehatan / Sumber daya kesehatan masih ada yang belum mampu memberikan pelayanan sesuai dengan standar (ANC terpadu). Kesimpulan Analisis input man and method pelaksanaan ANC di wilayah kerja Puskesmas Kecamatan IV Koto tahun 2016, masih ada tenaga kesehatan yang belum mencapai kualitas sesuai dengan standar, ini disebabkan oleh tahun lama kerja lebih dari 10 tahun sangat mempengaruhi bidan dalam memberikan pelayanan ANC termasuk kepatuhan menjalankan SOP yang tersedia, untuk itu butuh bimbingan teknis dari dinas kesehatan untuk menjamin kualitas pelayanan yang diberikan.
\end{abstract}

\section{Kata kunci: man and method Pelaksanaan ANC}

\section{ABSTRACT}

Increasing the number of abortion in the Working Area community health center of IV Koto in 2016 increases continuously, according to Putri (2018) causes by non-quality Ante Natal Care (ANC) and it is not suitable with an integrated ANC service standards of minister health rules No. 97 of 2014 for further research to find the cause of the ANC is not qualified. The purpose of this research is to analyze the input of man and method for the implementation of ANC in the working area of community health centre IV Koto District, Agam Regency. This research uses a qualitative research by using a system approach, data collection uses source triangulation techniques and data analysis uses the Huberman model. The results of the research find that there were still health workers / health resources who were not able to provide services in accordance with standards (integrated ANC) Conclusion Man and method input analysis of the implementation of ANC in the working area of Subdistrict IV Koto Public Health Center in 2016, there are still health workers who have not achieved quality in accordance with the standard, this is caused by years of working more than 10 years greatly influencing midwives in providing ANC services including compliance SOPs are available, for that we need technical guidance from the health department to ensure the quality of services provided.

Keywords: man and method Implementation of ANC

\section{PENDAHULUAN}

Pembangunan bidang kesehatan bertujuan meningkatkan kesejahteraan dan kualitas hidup masyarakat dunia untuk pencapaian Sustainable Developmen Goals (SDGs) 2030, khusus bidang kesehatan terdapat pada tujuan ke-3 dari 17 tujuan yang ada di SDGs, untuk kesehatan ibu indikator keberhasilan berporos pada Angka Kematian Ibu (AKI) dan pada tahun 2030 key point lebih ketat berada pada angka kurang dari 70 per 100.000 kelahiran hidup (WHO, 2015).Abortus adalah salah satu penyumbang AKI tersebut karena efek komplikasinya serta pelaksanaan abortus yang tidak aman (unsafe abortion). Abortus 
yaitu pengeluaran hasil konsepsi pada usia kehamilan kurang dari 22 minggu atau berat janin kurang dari 500 gram (Nurahmawati. E. 2011).

Abortus saat ini telah menjadi masalah kesehatan di seluruh dunia, terdapat 40-50\% kasus abortus dari seluruh wanita hamil, 60-70\% dari kasus abortus tersebut diketahui terjadi pada usia kurang dari 12 minggu, dan hanya $1 \%$ kejadian abortus terjadi setelah usia 12 minggu.

Guttmacher (2014) di New York tentang peningkatan kasus abortus menjelaskan bahwa peningkatan jumlah abortus disebabkan karena adanya budaya seks bebas serta aspek legalitas yang mendukung pelaksanaan aborsi di Negara tersebut (VOA Indonesia, 2014).

Indonesia sebagai negara

berkembang memiliki 5\% kejadian abortus (Profil Kesehatan Indonesia, 2014) dan

banyak faktor yang dapat mempengaruhinya seperti faktor janin, faktor maternal, faktor eksternal. (Ayuningtias, Taufiqy, \& Ika, 2011) dalam penelitiannya di Semarang tentang hubungan faktor maternal dengan kejadian abortus menemukan bahwa paritas menjadi faktor risiko paling dominan untuk terjadinya abortus, sedangkan (Kusniati, 2007)di Banyumas dalam penelitiannya tentang faktor ibu dengan kejadian abortus spontan menjelaskan bahwa usia ibu adalah faktor yang paling dominan penyebab munculnya abortus. Di Indonesia selain faktor maternal yang belum dapat dikendalikan sebagai penyebab abortus, faktor lainnya seperti kemampuan tenaga kesehatan dalam melaksanakan ANC berkualitas akan mampu mendeteksi faktor risiko yang dapat mengancam keselamatan ibu dan bayi, dan ini harus menjadi pembicaraan serius untuk mengendalikan faktor tenaga kesehatan yang secara langsung memberikan pelayanan kepada ibu hamil yang secara dini harus mampu mendeteksi kondisi ibu dan janin, agar tidak terjadi kegawatan pada ibu dan janin yang akan dilahirkan.
Kegawatan yang tersering terjadi adalah kematian janin usia kurang dari 29 minggu, (Anwar, 2005) mengatakan dalam penelitiannya tentang hubungan ANC berkualitas terhadap kematian janin menemukan ada hubungan yang signifikan dengan nilai OR 5.6, demikian juga dengan frekwensi pelaksanaan Ante Natal Care $(A N C)$ yang tidak teratur sebagaimana yang ditemukan oleh (Latifa, 2012) dalam penelitiannya tentang hubungan frekwensi pelaksanaan ANC dengan kejadian kematian janin menjelaskan bahwa ibu yang tidak teratur melakukan ANC memiliki risiko 2,6 kali peluang untuk kehilangan janinnya. Hasil-hasil penelitian

tersebut menggambarkan ANC mebutuhkan kerjasama 2 belah pihak antara ibu hamil dan tenaga kesehatan yang memberikan pelayanan ANC.

Kasus abortus di Sumatera Barat tercatat 5,8\% (Riskesdas, 2013), penelitian sebelumnya oleh Fransadewo (2015) tentang kejadian keguguran dan kehamilan yang tidak diinginkan di Indonesia menjelaskan bahwa kehamilan tidak diinginkan menjadi penyebab utama abortus di Sumatera Barat karena status ibu yang tidak bekerja yang hanya

menggantungkan penghasilan dari pendapatan suami. Di Kabupaten Agam kasus abortus mengalami peningkatan tiap tahunnya dimana tahun 2012 kasus abortus hanya 3.15\% kasus, tahun 2013 meningkat $3,27 \%$, tahun 2014 meningkat lagi menjadi $3,59 \%$ kasus, dan di tahun 2015 kasus abortus mencapai 3,92\%, dan Kecamatan IV Koto sampai September 2015 tercatat sebagai Kecamatan dengan kasus abortus tertinggi di Kabupaten Agam dengan 7,14\% atau 26 kasus dari 364 ibu hamil (Laporan Tahunan Dinas Kesehatan Kabupaten Agam, 2015).

Abortus merupakan cerminan dari rendahnya derajat kualitas kesehatan ibu hamil di Kecamatan IV Koto, juga merupakan output dari perjalanan sistem manajemen pelayanan kesehatan yang kurang optimal. Blum (1974) mengatakan bahwa kesehatan individu, kelompok, 
masyarakat dipengaruhi oleh genetik, lingkungan, perilaku, dan pelayanan kesehatan (Maulana, 2009). Dan hasil penelitian (Putri, 2016)di Kecamatan IV Koto menemukan ANC yang tidak berkualitas adalah faktor utama penyebab abortus, dimana pelayanan ANC yang diberikan tidak sesuai dengan (KemenKes Republik Indonesia, 2014)Permenkes No 97 tahun 2014tentang ANC terpadu. Dan hal ini menjadi dasar kelanjutan penelitian ini yaitu untuk melihat variabel apa yang dapat menyebabkan ANC tidak berkualitas di wilayah kerja Puskesmas Kecamatan IV Koto Kabupaten Agam Tahun 2017, sehingga kejadian abortus dapat diturunkan bahkan dihilangkan di wilayah kerja Puskesmas Kecamatan IV Koto Kabupaten Agam.

\section{METODE PENELITIAN}

Penelitian ini menggunakan desain kualitatif dengan pendekatan system dengan fokus sub sistem man dan method pelaksanaan ANC, jumlah informan yang digunakan sesuai dengan topik penelitian, kecukupan (saturasi) dimulai dari pengambil kebijakan, tenaga kesehatan pemberi pelayanan kesehatan serta ibu hamil sebagai pengguna pelayanan kesehatan ANC. Tehnik pengambilan data triangulasi sumber yaitu wawacara yang akan dipandu menggunakan probing-probing pertanyaan, telaah dokumen dengan memeriksa semua dokumen terkait pelayanan ANC dan observasi yang dilakukan langsung oleh peneliti ditempat penelitian, dengan hasil ditulis berbentuk matrik. Pengolahan data menggunakan huberman model dengan membuatkan transkrip data kemudian peneliti memilih data yang menjadi kata kunci atau mereduksi data, setelah itu peneliti menyajikan data dan penarikan kesimpulan.

\section{HASIL DAN PEMBAHASAN}

Aspek input man and method manajemen pelayananan ANC pada ibu hamil adalah segala sesuatu yang dibutuhkan untuk dapat melaksanakan pekerjaan pelayanan kepada ibu hamil yang meliputi sumber daya manusia kesehatan, buku sumber sebagai acuan pelaksanaan ANC (Azwar, 2010).

Aspek input digunakan sebagai pengukuran tidak langsung dari kualitas pelayanan. Hubungan antar aspek input dan kualitas pelayanan adalah hal penting dalam merencanakan, mendesain dan melaksanakan system yang dikehendaki, untuk dapat memberikan pelayanan kepada ibu hamil. Pengaturan karakteristik input yang digunakan mempunyai kecenderungan untuk mempengaruhi proses pelayanan sehingga ini agv ckan membuat kualitasnya meningkat atau berkurang. HL.Blum (1974) bila kualitas pelayanan kesehatan untuk ibu hamil menurun, maka akan dapat menurunkan derajat kesehatan ibu hamil, sehingga memunculkan beragam komplikasi selama kehamilan salah satunya adalah abortus.

Berdasarkan hasil penelitian diketahui bahwa terdapat beberapa komponen aspek input yang telah disediakan oleh Pemerintah, Pemerintah Daerah maupun Dinas Kesehatan Kabupaten Agam untuk menunjang pelaksanaan pelayanan kesehatan yang berkualitas kepada ibu hamil yaitu:

\section{Tenaga Kesehatan}

Kesehatan sebagai salah satu unsur kesejahteraan umum harus diwujudkan sesuai dengan cita-cita bangsa Indonesia sebagaimana dimaksud dalam Pembukaan Undang-Undang Dasar 1945 melalui

pembangunan nasional yang berkesinambungan berdasarkan Pancasila dan Undang-Undang Dasar 1945. Pada Undang-Undang kesehatan No.36 Tahun 2009, Bab VI menjelaskan tentang upaya kesehatan untuk mewujudkan derajat kesehatan bagi masyarakat yang setinggitingginya, maka diselenggarakan upaya kesehatan terpadu dan menyeluruh baik kesehatan perorangan maupun upaya kesehatan masyarakat. Upaya kesehatan tersebut dilakukan dalam bentuk kegiatan promotif, preventif, kuratif dan 
rehabilitative, yang dilaksanakan secara terpadu, menyeluruh, dan berkesinambungan

Penyelenggaraan upaya kesehatan sebagaimana dimaksud dilaksanakan melalui kegiatan pelayanan diantaranya adalah pelayanan kesehatan reproduksi. Dalam pelaksanaannya upaya pelayanan kesehatan tersebut didukung oleh sumber daya kesehatan dengan harus memperhatikan fungsi sosial, nilai, norma agama, sosial budaya, moral, dan etika profesi.

Ketersediaan sumberdaya kesehatan dilihat dari struktur organisasi terdapat beberapa posisi yang diisi oleh orang yang sama, jumlah tenaga yang kurang tersebut terutama untuk tenaga profesi bidan dan perawat, bila dibandingkan dengan jumlah penduduk Kecamatan IV Koto yang mencapai 23. 043 jiwa. Selain kuantitas tenaga kesehatan yang masih kurang

kualitas tenaga kesehatan yang memberikan pelayanan kesehatan menurut hasil wawancara baru sekitar $75 \%$ tenaga kesehatan yang memepu memberikan pelayanan ksehatan yang berkualitas kepada masyarakat terutama dalam melakukan skrining faktor risiko dalam pelayanan kesehatan ibu hamil.

Berdasarkan hasil wawancara ditemukan masih rendahnya kemampuan tenaga kesehatan melakukan pelayanan kesehatan yang berkualitas kepada ibu hamil, sehingga tenaga kesehatan belum mampu sensitive mendeteksi faktor risiko yang dapat menimbulkan komplikasi pada kehamilan, persalinan dan setelah bersalin kepada ibu.

Menurut Kepala Bidang pelayanan kesehatan Kabupaten Agam menyatakan kasus abortus yang terjadi di Kabupaten Agam selain faktor maternal juga disebabkan oleh kualitas tenaga kesehatan yang masih belum mampu sensitive mendeteksi faktor risiko dan juga rendahnya kualitas pelayana yang diberikan kepada ibu hamil sehingga abortus belum dapat dikendalikan.
Lipsky dalam Purwanto (2012) mengemukakan bahwa pelaksanaan yang berhubungan dengan masyarakat akan sangat berperan mewujudkan tujuan kegiatan dilapangan, terlebih tenaga kesehatan lulusan tidak secara otomatis langsung dapat menjalankan tugas dan fungsinya di pelayanan kesehatan, tetapi masih memerlukan orientasi, ataupun pelatihan.

Untuk itu dengan rendahnya kualitas sumber daya kesehatan yang dimiliki oleh Kabupaten Agam membuat Dinas Kesehatan mengambil kebijakan untuk meningkatkan kualitas SDM kesehatan dengan melakukan berbagai upaya untuk meningkatkan kualitas SDM ini, salah satunya adalah dengan memberikan pelatihan, workshop, studi banding, bahkan desiminasi ilmu bagi seluruh tenaga kesehatan baik sebagai pengelola maupun sebagai pelaksana pelayanan kesehatan kepada ibu hamil.

Upaya peningkatan kualitas SDM kesehatan dilaksanakan menggunakan dana yang di alokasikan dari APBD, anggaran tersebut menurut hasil wawancara dengan Kepala Bidang Pelayanan Kesehatan digunakan untuk peningkatan kualitas SDM baik sebagai pelaksana maupun pengelola, dan pelatihan usaha tersebut belum menampakkan optimalnya, namun hasil tersebut baru akan bisa kita lihat ditahun berikutnya, apakah upaya ini benar-benar efektif untuk menurunkan kasus abortus yang ada di Kabupaten Agam khususnya Kecamatan IV Koto.

\section{Metode}

Hasil penelitian menggunakan wawancara, observasi dan telaah dokumen ditemukan sudah optimalnya metode pelayanan kesehatan yang diberikan oleh tenaga kesehatan untuk ibu hamil karena sudah diiringi dengan SOP dan bimbingan teknis yang dilakukan kepada seluruh tenaga kesehatan yang ada di Wilayah Kerja Puskesmas Kecamatan IV Koto. Metode manajemen pelaksanaan pelayanan kesehatan yang diberikan kepada ibu hamil 
telah sesuai dengan perundang-undangan dimana ada 2 pelaksanaan dalam manajemen pelayanan kesehatan untuk ibu hamil, yaitu 10 pelayanan yang wajib diterima oleh ibu yang lebih dikenal dengan 10T, dan metode bimbingan teknis yang

digunakan untuk meningkatkan kemampuan tenaga kesehatan dalam memberikan pelayanan kepada ibu hamil

Butuh pengembangan strategi untuk dapat menjaring seluruh ibu hamil agar masuk kedalam buku kohort K-1 beserta pencapaian seluruh pelayanan agar diterima oleh ibu hamil, hasil wawancara dengan tenaga kesehatan pemberi pelayanan kesehatan kepada ibu hamil mengatakan bahwa butuh strategi jemput bola atau sweeping agar semua sasaran dapat di jangkau dengan pelayanan 10T, sedangkan untuk metode kendali mutu pelayanan dikendalikan menggunakan metode PWS-KIA sebagai bentuk pencatatan dan pelaporan.

Namun sampai saat sekarang belum ada metode pengkoordinasian dan pengelolaan pelayanan kesehatan untuk ibu hamil dari Pemerintah Daerah (camat) sampai dengan wali Nagari seperti sebuah metode agar pelaksanan pengawasan ibu hamil melibatkan kegiatan PKK (dasawisma) sebagai bentuk pemberdayaan masyarakat.

Permenkes No.97 Tahun 2014 pada BAB VII dijelaskan tentang pemberdayaan masyarakat untuk percepatan pencapaian derajat kesehatan ibu yang optimal diperlukan peran serta masyarakat baik secara perorangan maupun terorganisasi. Salah satunya adalah Program Perencanaan Persalinan Dan Pencegahan Komplikasi (P4K) sebagaimana dimasud dalam UU peran masyarakat salah satunya dapat berupa kegiatan kelas ibu hamil di daerah Kecamatan IV koto belum mampu dilaksanakan oleh Puskesmas dan Masyarakat dalam bentuk Nagari Siaga karena belum didukung oleh metode yang adekuat.

Hasil wawancara dengan Kepala Puskesmas Kecamatan IV Koto diungkap bahwa belum ada metode yang dianggap tepat untuk dapat menggerakkan masyarakat sehingga dapat berjalan sinergis dengan kegiatan di Nagari, sehingga kita bergerak sendiri-sendiri, padahal kita memiliki tujuan kerja dan program kerja yang berdekatan.

Hasil Observasi dan telaah dokumen belum ditemukan adanya metode kerja yang mensinergiskan kegiatan Puskesmas dengan kegiatan di Nagari, misalnya kelas ibu hamil tidak semua Nagari mampu melaksanakan kelas ibu hamil, tidak semua Nagari juga mampu memberdayakan masyarakatnya untuk mau terlibat dalam kelas ibu hamil, dan dalam kegiatan kelas ibu hamil kalau ada dilaksanakan belum ada campur tangan tokoh masyarakat yang mampu menggerakkan masyarakat.

Belum adanya pengintegrasian kegiatan Puskesmas dengan kelompok masyarakat melemahkan pencapaian program pelayanan kesehatan untuk ibu hamil karena dengan luasnya wilayah kerja dan minimnya jumlah tenaga kesehatan yang berada diwilayah kerja belum mampu secara optimal mengawasi keadaan ibu hamil terutama yang berisiko, untuk itu perlu kerjasama dengan PKK khususnya pada kelompok kerja IV tentang kesehatan dan kelompok dasawisma agar penjaringan dan pemantauan ibu hamil dapat optimal.

Methode sangat berhubungan dengan dengan ketersediaan sarana dan prasarana dalam pelaksanaan pelayanan kesehatan kepada ibu hamil telah dilengkapi oleh Dinas Kesehatan sendiri menggunakan dana BOK maupun dana

JKN yang berasal dari pusat. Pendistribusian sarana dan prasaran menurut pengakuan Kepala Bidang Pelayanan Kesehatan telah didistribusi dengan merata, namun pada Daerah Wilayah Agam Barat pendisitribusi tersebut terkendala oleh karena rendahnya kesadaran masyarakat untuk mau menerima fasilitas pelayanan kesehatan ada di wilayah mereka, dan ini adalah kendala dalam pendistribusian fasilitas kesehatan. 
Di Puskesmas Kecamatan IV Koto sarana dan prasana kesehatan sudah

tersedia lengkap terutama untuk pelaksanaan pelayanan kesehatan minimal kepada ibu hamil, demikian juga dengan dalam penyediaan barang habis pakai dapat diminta kembali kapan saja sesuai dengan kebutuhan dengan syarat mengisi lembar permintaan bahan, kecuali obat memang pendistribusian setiap 3 bulan sekali, dan pendistribusian obat juga tergantung dengan kebutuhan masyarakat. Bila dalam permintaan peralatan kesehatan Dinas Kesehatan belum memiliki bahan tersebut maka Puskesmas berhak membeli sendiri menggunakan dana JKN, sesuai dengan perencanaan yang telah dibuat dalam perencanaan tahunan Puskesmas maupun koordinator program..

Beberapa aspek yang ada mengisi input ditemukan beberapa komponen input yang menjadi permasalahan yaitu jumlah tenaga kesehatan khususnya bidan yang langsung memberikan pelayanan kesehatan di masyarakat masih kurang bila dibandingkan dengan rasio penduduk dimana didapatkan perbandingan 1/1280, dengan perbandingan normal 1/1000. Selain itu masih rendahnya kemampuan tenaga kesehatan melakukan pelayanan

kesehatan khususnya ANC yang berkualitas kepada ibu hamil.

Hasil wawancara dengan Kepala Seksi Kesehatan Ibu Dan Anak menyatakan bahwa di Dinas Kesehatan pun tenaga kesehatan khususnya bidan belum ada tambahan atau tidak ada tenaga bidan yang standby di Dinas Kesehatan untuk di tempatkan di PuskesmasPuskesmas yang membutuhkan terutama Puskesmas IV Koto.

Hasil wawancara dengan penanggung jawab KIA menyatakan walaupun bidan kita ada 23 orang namun yang aktif di pelayanan KIA hanya 15 orang karena alasan kurang sehat, dan titipan pejabat.

Hasil wawancara dengan Kepala Bidang Pelayanan Kesehatan Dasar dan Penanggung Jawab KIA menyatakan baru
$70 \%-75 \%$ tenaga kita yang mampu mendeteksi faktor risiko ibu hamil dengan cepat dan tepat, begitu juga dengan kemampuan tenaga kesehatan terutama bidan dalam melaksanakan pelayanan kesehatan kepada ibu hamil khususnya pelayanan ANC yang belum sesuai dengan SOP yang telah disediakan oleh Dinas Kesehatan, hal ini terjadi karena masa kerja yang belum matang / serta tingkat pendidikan rata-rata Diploma III.

Untuk itu dibutuhkan kerjasama dan komitmen bersama oleh masingmasing bagian yang terlibat seperti:

\section{a) Dinas kesehatan}

Peningkatan mutu pelayanan dapat dilakukan dengan cara meningkatkan system manajemen pelayanan kesehatan ibu dengan melaatih kembali melalui bimbingan teknis, terutama kepada tenaga kesehatan yang memberikan pelayanan kesehatan kepada ibu khususnya dengan masa kerja kurang dari 10 tahun (Aliah.A, 2015), terutama untuk kesehatan ibu hamil terhadap kejelian dalam melaukan deteksi dini sangat kurang, sehingga tidak terbaca masalah kesehatan dasar ibu hamil yang dapat mengakibatkan kegawatan janin bahkan abortus.

Efektifitas pengaturan jumlah tenaga kesehatan yang disesuaikan dengan persentase jumlah tenaga senior lebih dari 10 tahun yang harus melakukan pendampingan untuk tenaga kesehatan dengan masa kerja kurang dari 10 tahun, demikian juga dengan perbandingan jumlah penduduk agar tenaga kesehatan berpengalaman di tempatkan di daerah rawan agar mereka mandiri dalam mengerjakan dan mengambil keputusan untuk tindakan, sehingga mampu memberikan pelayanan yang maksimal. Pengaturan beban kerja juga perlu diperhitungkan sehingga tidak ada lagi alasan tenaga kesehatan

memberikan pelayanan kesehatan kepada ibu hamil tergesa-gesa sebagai mana hasil observasi peneliti dalam 
pemerian pelayanan kANC yang dilakukan, dengan meminimalkan beban kerja petugas kesehatan berdasarkan jumlah ratio perbandingan dengan jumlah penduduk. Kualitas tenaga kesehatan dengan beban kerja rasio yang seimbang $1 / 1000$ untuk tenaga kesehatan bidan lebih efektif untuk melakukan bimbingan teknis lebih intens terutama pada tindakan deteksi dini faktor risiko ibu hamil, dan peningkatan kemampuan tenaga kesehatan dalam memberikan pelayanan kesehatan untuk ibu hamil khususnya tindakan ANC yang berkualitas akan lebih terfokus dengan mengadakan desiminasi ilmu terkait.

Peningkatan mutu pelayanan juga dapat ditingkatkan dengan melibatkan tenaga kesehatan lain seperti tenaga medis yang ada di Puskesmas minimal pada kunjungan kedua kehamilan dan ketiga sehingga penjaringan faktor risiko dapat di tekan pada usia gestasi kurang dari 12 minggu atau lebih dari 12 minggu pada kunjungan berikutnya sampai 22 minggu karena usia gestasi ini adalah jadwal usia gestasi tersering menghadapi abortus.

Peningkatan kualitas kerjasama dengan Pemerintah Daerah seperti Camat perlu menjadi perhatian, karena Pemerintah Daerah memiliki peran dalam garis lingkungan, dimana secara alur system manajemen kesehatan turut mempengaruhinya. Melakukan MOU dengan melibatkan langsung Pemerintah Daerah (Camat) diharapkan dapat mengsinergiskan kaitan program kerja yang ada di Kecamatan dengan program kerja yang ada di Puskesmas yang ada di seluruh wilayah kerjanya di Kabupaten Agam sehingga memiliki satu visi yang sama yaitu meningkatkan kesejahteraan masyarakat.

Hubungan kerjasama ini dapat tertuang dalam Peraturan Penemrintah Daerah (camat) yang nantinya akan terus ditindak lanjuti oleh Pemerintah Nagari. Nagari bersama kelompok PKK yang memiliki beberapa kelompok kerja di masyarakat salah satunya dibidang kesehatan adalah kelompok kerja kesehatan yang berada pada kelompok IV (pokja IV) yang nantinya sebagai tindak lanjut dan rencana jangka menengah seperti yang disebutkan oleh Kepala Puskesmas dalam wawancara kepada peneliti bahwa akan ada kader yang dilibatkan sebagai pengawas ibu hamil yang berada pada kelompok dasawima terdekat selain keluarga (suami dan keluarga) sehingga ada nampak dukun dukungan yang nyata dari lingkungan (stake holders) terhadap proses manajemen kesehatan khususnya kesehatan ibu hamil.

Dengan adanya beberapa pergeseran paradigma tentang tugas dan fungsi Puskesmas yang selama ini secara teoritis lebih kepada pengembangan promosi kesehatan dan usaha preventif untuk dapat dikembalikan sebagaimana mestinya sehingga promosi kesehatan yang menjadi tugas utama bidang promosi kesehatan kembali aktif dan berjalan.

Hasil wawancara peneliti dengan bidang prmosi kesehatan untuk pelaksanaan promosi dibadng KIA khsusnya ibu hamil telah kami serahkan ke bidangnya di KIA sehingga mereka secara mandiri melaksanakan kegiatan promosi tersebut begitu juga dengan pengadaan fasilitas dan sarana prasana yang dibutuhkan langsung bidang terkait yang menjadi penyedia. Dan bidang promosi menjadi pelaksana bila ada event maupun kasus luar biasa pada issue utama seperti kejadian Filariasis menjadi kejadian luar biasa pada trimester ini maka bidang promosi kesehatan akan mengadakan penyuluhan keliling menggunakan mobil Puskesmas keliling untuk memberitahukan kepada masyarakat dan menyiapkan dan menfasilitasi proses pelayanan.

Hasil analisis peneliti perlu

kiranya alur yang jelas dalam menetapkan kembali fungsi

Puskesmas dan meminimalkan 
pelayanan kuratif dan rehabilitative sehingga kasus komplikasi kehamilan maupun persalinan yang ada dalam lingkup kesehatan ibu hamil pada program KIA dapat diminimalkan, karena fungsi Puskesmas sebagai pemberi pendidikan kesehatan untuk meningkatkan pengetahuan masyarakat yang merupakan gerakan awal agar masyarakat mampu melakukan pencegahan baik dibimbing oleh tenaga kesehatan maupun secara mandiri dapat dimaksimalkan.

\section{b) Kepala Puskesmas}

Kepala Puskesmas sebagai pengendali dan penjamin mutu Puskesmas dalam memberikan pelayanan kesehatan khususnya kepada ibu hamil meningkatkan pelaksanaan bimbingan teknis bimbingan teknis atau pun desiminasi ilmu menjadi pilihan utama karena tidak setiap saat pelatihan khusus untuk bidan dapat dilaksanakan oleh Dinas Kesehatan. Penyajian ilmiah seperti lokakarya mini pengelolaan kasus terbanyak dapat menjadi topik pilihan dalam pelaksanaan lokakarya ilmiah di Puskesmas sebagai tindakan awal dalam meningkatkan kualitas tenaga kesehatan dalam menghadapi ibu hamil.

Kurangnya tenaga kesehatan khususnya bidan yang memberikan pelayanan kesehatan kepada ibu hamil menjadi permasalahan utama pada Puskesmas Kecamatan IV Koto sehingga terdapat double Job dan berimbas kepada penurunan kualitas pelayanan kepada ibu hamil karena di lapangan kenyataan bidan tidak hanyya melakukan fungsinya sebagai bidan tetapi merangkap menjadi tenaga kesehatan yang lain dan merangkap sebagai tenaga administrasi yang mengelola system manajemen Puskesmas Pembantu, Pos Kesehatan Nagari sendiri.
Pemberian reward untuk bidan dengan minimal komplikasi kehamilan dan persalinan dapat dijadikan standar out put yang harus dicapai oleh setiap Puskesmas Pembantu, sehingga diharapkan pengawasan kepada ibu hamil berisiko bisa lebih intensif.

Begitu juga kerjasama dengan Pemerintah Daerah untuk dapat sesegera mungkin melaksanakan kerjasama lanjutan selain sekolah dan juga Kantor Urusan Agama (KUA) yaitu kepada Pemerintah Daerah yaitu Kecamatan untuk segera membuat peraturan atau kebijakan yang mendukung program kesehatan yang ada di wilayah kerjanya, yang nantinya akan ditindak lanjuti oleh Nagari-Nagari dan Lembaga Pemberdayaan Masyarakat (LPM) termasuk kelompok PKK.

Untuk itu butuh kebijakan baru dan mengeluarkannya dalam bentuk Surat Keputusan (SK) untuk penunjukkan kader peduli Ibu hamil atau kader sayang ibu yang menyebar menjadi kelompok dasawisma.

\section{c) Bidan Pelaksana}

Minimnya jumlah bidan bila disuatu daerah wilayah kerja yang merangkap mewakili semua jenis tenaga kesehatan tidak serta merta hanya melakukan tugas sebagai bidan, sebagai mana pemberi pelayanan kesehatan kepada ibu hamil terutama untuk pelayanan ANC menjadi permasalahan utama di wilayah kerja Puskesmas Kecamatan

IV Koto sebagaimana yang dikeluhkan oleh Kepala Puskesmas dan Penanggung jawab KIA, untuk itu dibutuhkan tenaga bidan yang lebih peka dengan kondisi masyarakat sekitarnya agar dapat lebih sensitive lagi dalam melakukan skrining kepada calon ibu hamil ibu hamil. Rendahnya kualitas pelayanan yang diberikan oleh tenaga kesehatan 
sebagai pemberi pelayanan kesehatan kepada ibu hamil menjadi permasalahan utama pada penelitian ini, untuk itu diharapkan kepada tenaga bidan untuk dapat melaksanakan desiminasi asuhan kebidanan pada kasus terbanyak dan menjadikan kasus tersebut rujukan yang dapat membantu pelaksanaan kasus nyata, sehingga tenaga bidan mendapatkan panduan yang baku yang telah disepakati bersama terhadap yang dihadapi.

Selain manajemen kasus yang yang berkualitas, kerjasama dengan Pemerintah nagari perlu kiranya terus ditingkatkan oleh bidan dalam mendukung segala program yang menunjang kesehatan ibu hamil, terutama pelaksanaan kelas ibu hamil dan kelas suami sebagai wadah meningkatkan pengetahuan dan bertukar pengalaman antar ibu hamil maupun suami yang memiliki istri hamil sehingga pengambilan keputusan yang biasanya dipegang oleh suami dapat berjalan cepat dan tepat.

Pengadaan kelas ibu hamil selama peneliti melakukan penelitian di wilayah kerja Puskesmas Kecamatan IV Koto terlihat memang memberikan dampak yang positif terhadap kejadian abortus diwilayah itu, sebagai contoh di wilayah Sungai Jariang pelaksanaan kelas ibu hamil dan kelas suami yang memiliki istri hamil berjalan sangat baik, dan hasil out put ditemukan memang kejadian abortus adanyalah yang laing sedikit yaitu hanya 1 orang ibu hamil yang abortus.

Kenyataan berbanding terbalik dengan daerah Jambak yang hasil wawancara dengan bidan pelaksana keberadaan kelas ibu hamil maupun kelas suami yang memiliki istri hamil tidak berjalan atau tidak ada dengan alasan bidan belum sempat melakukan kegiatan tersebut dan jumlah kehamilan yang hanya sedikit di tahun ini. Hasil observasi peneliti dengan ibu hamil dan suami memang mendapatkan gambaran tingkat pengetahuan yang rendah tentang kehamilan, begitu juga dengan out put peneliti mendapatkan 6 orang ibu hamil mengalami abortus di tahun 2015.

Dengan

melakukan perbandingan tersebut pengembalian fungsi Puskesmas untuk lebih meningkatkan kegiatan promosi kesehatan dan pencegahan memiliki peran yang memberikan pengaruh terhadap pembentukan derajat kesehatan masyarakat khususnya ibu hamil.

Belum ada metode pelaksanaan, pengkoordinasian dan pengelolaan pelayanan kesehatan untuk ibu hamil dari Pemerintah Daerah (camat) sampai dengan wali Nagari seperti sebuah metode agar pelaksanan pengawasan ibu hamil melibatkan kegiatan PKK (dasawisma) menjadi permasalahan dalam penelitian ini karena dapat mempengaruhi beban kerja dan pelayanan kesehatan yang diterima oleh masyarakat (ibu hamil).

\section{d) Pemerintah Daerah (Kecamatan)}

Tidak bersinerginya program kerja yang ada di Kecamatan dengan Program Kerja Puskesmas membuat kesenjangan atau perlambatan peningkatan kesejahteraan masyarakat yang telah menjadi permasalahan dalam peneluan penelitian ini, sehingga tujuan bersama pembangunan sulit tercapai. Untuk itu butuh keluarnya sebuah kebijakan yang dapat mendukung pelaksanaan pencapaian tujuan tersebut yang dapat ditindak lanjuti oleh Pemerintah nagari sebagai unit pelaksanan, sehingga ada satu visi dengan misi untuk kesejahteraan masyarakat. 


\section{e) Keluarga Ibu Hamil}

Pelayanan kesehatan yang telah diberikan oleh tenaga kesehatan tidak diiringi oleh peran aktif dari keluarga seperti suami menjadi permasalahan dalam penelitian ini. Pendidikan kesehatan yang tidak semuanya suami mendapatkan karena kehadiran

suami yang minim dalam mengantarkan istri melakukan pelayanan ANC dan mendengarkan pendidikan kesehatan yang diberikan oleh tenaga kesehatan dapat menurunkan tingkat pengetahuan suami tentang kehamilan. Keaktifan masyarakat dalam Upaya Kesehatan Berbasis Masyarakat (UKBM) yang tidak merata diseluruh wilayah mengalihkan persepsi suami dalam mengikuti kelas ibu hamil yang telah disediakan oleh tenaga kesehatan membuat perilaku yang buruk bagi suami hal ini tercermin dari hasil

penelitian kuantitatif yang menemukan hampir seluruh suami tidak melaksanakan perannya sebagai suami dari ibu yang sedang hamil. Untuk itu perlu arahan dari tenaga kesehatan agar dapat meningkatkan kepedulian suami terhadap perawatan kehamilan istrinya. Sehingga perlu peran suami seperti mengingatkan istri untuk melakukan seluruh

perawatan tersebut seperti mengingatkan makan makanan yang sehat dan seimbang, meringankan kerja rumah tangga istri dan mengingatkan perawatan kehamilan.

\section{f) Pemberi Kerja}
Sebagian besar ibu hamil di Wilayah kerja Puskesmas Kecamatan IV Koto adalah ibu hamil yang memiliki kerja tambahan selain ibu rumah tangga, untuk itu butuh pengertian dan tanggung jawab bagi pemberi pekerjaan karena secara statistic ibu hamil yang berkerja diwilayah kerja Puskesmas kecamatan IV Koto memiliki

hubungan yang signifikan terhadap kejadian abortus, dan ini juga menjadi permasalahan bagi penanggung jawab kesehatan.

Hal ini terjadi karena sepauh ibu hamil diwilayah kerja Puskesmas Kecamatan IV Koto memiliki status ekonomi miskin, sehingga kondisi ini mendesak ibu hamil untuk bekerja dan mencari alternative lain pekerjaan selain buruh lading yang dianggapnya tidak membahayakan kehamilan.

Pengetahuan yang rendah dari suami dan istri, tingkat ekonomi yang rendah serta minimnya pendidikan kesehatan yang menjelaskan bahwa ada hubungan yang signifikan antara ibu yang bekerja dengan kejadian

abortus membuat ibu tetap melakukan pekerjaan rutinitasnya yang berbahaya tersebut.

Untuk itu pemberi pekerjaan untuk dapat mengurangi atau membatasi dan kalau bisa tidak menerima karyawan hamil demi

$\begin{array}{llr}\text { mengurangi } & \text { kejadian } & \text { abortus } \\ \text { diwilayah } & \text { kerja } & \text { Puskesmas } \\ \text { Kecamatan IV Koto. } & \end{array}$

\section{KESIMPULAN}

Rendahnya kualitas ANC yang diberikan dapat disebabkan oleh masa kerja tenaga kesehatan kurang dari 19 tahun yang belum mapu memberikan pelayanan ANC berkualitas dalam segi kemampuan melakukan deteksi dini kesehatan ibu hamil dan janin. Hasil observasi belum ada pengintegrasian program kesehatan antara kecamatan dan Puskesmas khususnya Tenaga kesehatan secara kuatitas masih kurang bila dibandingkan dengan rasio penduduk 1/1280, demikian juga dengan kualitas tenaga kesehatan baru 70-75\% disebabkan masa kerja kurang dari 10 tahun juga ketidak patuhan dalam menjalankan setiap urutan SOP yang telah disusun mepengaruhi pelayanan kesehatan kepada ibu hamil, sehingga kurang mampu menjaring faktor risiko kehamilan dan 
menjadi penyebab di subsistem man dan metode terjadinya masalah kejadian abortus yang utama di wilayah ini.

Ketidak tersediaan tenaga kesehatan yang berkualitas yang mampu menjawab kebutuhan masyarakat belum memadai di dinas kesehatan Kabupaten Agam. Maka solusi yang ditawarkan peneliti adalah bimbingan teknis yang berkesinambungan untuk tenaga kesehatan menjadi pilihan utama untuk tenaga kesehatan dalam menjaga mutu pelayanan kesehatan yang diberikan.

\section{UCAPAN TERIMA KASIH}

Ucapan teima kasih tak terhingga kepada Ketua STIKes Fort De Kock Bukittinggi yang telah memberikan kesempatan kepada penulis untuk melakukan penelitian ini, Bapak Kepala dinas Kesehatan Kabupaten Agam beserta jajarannya yang telah memberikan izin kepada peneliti melakukan penelitian diwilayah kerja yang bapak pimpin.

\section{REFERENSI}

Abu.A., Kusumawati.Y., Werdani.K. 2015. Hubungan Karateristik Bidan Dengan Mutu Pelayanan ANC Berdasarkan Standar Operasional. Jurnal Ilmu Kesehatan Masyrakat Andalas 10 (1) 94-100.

Anwar, C. (2005). Hubungan Kualitas pemeriksaan Antenatal dengan kematian perinatal. Semarang. Ayuningtias, T., Taufiqy, M., \& Ika, D. (2011). Hubungan Faktor Maternal Dengan Kejadian Abortus Inkompletus, 1.

Azwar.A. 2010. Pengantar Administrasi Kesehatan. Binarupa Aksara. Tanggerang

Eni Nur Rahmawati. 2011. Ilmu Praktis Kebidanan. Victory Inti Cipta. Surabaya

Erpan, L. N., Trisnantoro, L., Studi, P., Kesehatan, I., Kedokteran, F., \& Mada, U. G. (2012). Koordinasi Pelaksanaan Pembiayaan Program
Kesehatan Ibu Dan Anak Di Kabupaten Lombok Tengah NTB, 1(1), 42-51.

Fransadewo. 2012. Kejadian Keguguran Dan Kehamilan Tidak Di Inginkan Di Indonesia. ejournal.litbang.depkes.go.id. Jakarta

KemenKes Republik Indonesia. (2014). No Title, 97.

Kusniati. (2007). Hubungan beberapa faktor ibu dengan kejadian abortus spontan di Rumah Sakit Ibu Dan ANak An Ni'mah Kecamatan Wangon Kabupaten Banyumas, (June), 1.

Laporan tahunan Dinas Kesehatan Kabupaten agam Tahun 2015

Latifa, N. (2012). kehamilan dengan kejadian kematian neonatal ( analisis data sdki 2007 ) tesis.

Massie. (2009). kebijakan kesehatan: Pusat Penelitian Dan Pengembangan Dan Kebijakan Kesehatan, 12 no 4(23), 409-417.

Maulana. Heri. 2009. Promosi kesehatan. EGC.Jakarta

Peraturan Presiden No 61 tahun 2014 tentang kesehatan reproduksi

Peraturan Daerah Kabupaten Agam No 4 tahun 2011 Tentang Tugas dan fungsi Dinas Kesehatan dalam merumuskan kebijakan tehknik dan pelayanan bidang kesehatan

Purwanto, E.A. 2012. Implemetasi Kebijakan Publik (Konsep Dan Aplikasinya Di Indonesia). Cetakan Pertama. Gava media. Yogyakarta

Putri, L. M. (2016). Faktor risiko Utama meaternal Penyebab Abortus Di Puskesmas Kecamatan IV Koto Kabupaten Agam, 3(11), 383-399.

Sulaeman. 2009. Manajemen Kesehatan. Gajah Mada University Press. Yogyakarta

UU Kesehatan No 36 tahun 2009 tentang Mewujudkan derajat kesehatan masyarakat setinggi tingginya VOA Indonesia. 2014. Abortus Di Amerika Turun Ke Tingkat Terendah. Amerika

WHO, 2015.PBB Di Indonesia. Jakarta 